\title{
Pore pressure effects on strength and elasticity of ornamental stones
}

\author{
Supattra Khamrat, Sarayuth Archeeploha, Kittitep Fuenkajorn* \\ Geomechanics Research Unit, Institute of Engineering, Suranaree University of Technology, \\ Muang District, Nakhon Ratchasima 30000 Thailand
}

*Corresponding author, e-mail: kittitep@sut.ac.th

Received 19 Feb 2015

Accepted 18 Mar 2016

\begin{abstract}
This experimental study determines the effects of pore pressure on the compressive strengths and elasticity of six ornamental stones. An approach to determine the pore pressure in low porosity rocks is presented. Rectangular rock specimens $\left(50 \times 50 \times 100 \mathrm{~mm}^{3}\right)$ under dry and wet conditions were axially loaded under different rates from 0.001-10 MPa/s using a polyaxial load frame. The confining pressures ranged from 0 to $12 \mathrm{MPa}$. Wet granite, marl, marble, Phra Wihan sandstone, Phu Phan sandstone, and siltstone specimens have an average water content of $0.14 \%$, $2.7 \%, 0.09 \%, 2.05 \%, 4.9 \%$, and $1.5 \%$, respectively. Compressive shear failure was observed in specimens under slow loading rate while extension failure was found in specimens under high loading rate. The strength values of the wet specimens were lower than those of the dry ones, particularly under the high confining pressure and loading rates. The strength values obtained from the dry testing were used to quantitatively calibrate the loading rate effect from the wet strengths, and hence the effect of pore pressure could be calculated. The pore pressures notably reduced the compressive strength and elastic modulus, and slightly increased Poisson's ratio of the rocks tested.
\end{abstract}

KEYWORDS: loading rate, decorating stone, water content, elastic modulus

\section{INTRODUCTION}

The compressive strength and deformability of ornamental stones are important parameters for the applications of decorating and building stones ${ }^{1-4}$. Water content can remarkably reduce the rock strength after only $1 \%$ water saturation ${ }^{5,6}$. The strength of a wet specimen is lower than that of a dry one $\mathrm{e}^{1,3,7-10}$ and the tensile strength of rocks under saturated conditions is lower than that under dry conditions $^{11,12}$. The influence of water on deformability of rocks is reflected as a reduction of Young's modulus and an increase of Poisson's ratio ${ }^{3,7,13,14}$. The best relations between uniaxial compressive strength and elastic modulus with water content are found to be exponential functions $s^{5,6,9,14}$. The uniaxial compressive strength and elastic modulus also decrease with increasing porosity ${ }^{4,15-17}$. A simplified model for crack damage stress $\left(\sigma_{\mathrm{cd}}\right)$ in terms of porosity, elastic modulus, and Poisson's ratio has been obtained ${ }^{18}$. The model shows that when porosity decreases, the elastic modulus increases, $\sigma_{\mathrm{cd}}$ increases rapidly and approaches a maximum value. The influence of water on the strength of relatively high porosity rocks is well known. Under dry conditions, however, the quantitative effects of the pore pressures on the mechanical properties of low porosity rock have rarely been studied. This is due to the fact that the effects of pore pressure in low porosity rocks are difficult to measure accurately ${ }^{19}$. Experimental data obtained in the 1960's concluded that for low porosity rock specimens the effective confining pressure effect is more important than pore pressure effects ${ }^{20-22}$.

The objective of this study is to experimentally determine the effects of pore pressure on the compressive strengths and elasticity of six Thai ornamental stones. The effects of pore pressure on the rock strength and deformability are calculated under various loading rates and confining pressures. Both dry and wet specimens were tested. Mathematical relationships are proposed to correlate the rock mechanical properties with the pore pressure.

\section{METHODS}

\section{Sample preparation}

The rock samples used in this study are Tak granite $^{23}$, Lopburi marl and marble ${ }^{24}$, Phu Phan (PP) sandstone, Phra Wihan (PW) sandstone, and Phu Kradung (PK) siltstone ${ }^{25}$. They are widely used as support columns, monuments, temple walls, and footpaths. Table 1 gives the mineral compositions of the rock samples ${ }^{26}$. For each rock type, 40 spec- 
Table 1 Brief mineral compositions of rock samples.

\begin{tabular}{ll}
\hline Rock name & Mineral compositions and crystal/grain sizes (in mm) \\
\hline Tak granite & $40 \%$ plagioclase $(0.5-1 \mathrm{~mm}), 30 \%$ quartz $(2-5 \mathrm{~mm}), 5 \%$ orthoclase $(3-5 \mathrm{~mm})$, \\
& $3 \%$ amphibole $(1-2 \mathrm{~mm}), 2 \%$ biotite $(1-2 \mathrm{~mm})$ \\
Lopburi marl & $65 \%$ calcite $(1-5 \mathrm{~mm}), 35 \%$ clay minerals $(0.1-0.3 \mathrm{~mm})$ \\
Lopburi marble & $100 \%$ calcite $(1-2 \mathrm{~mm})$ \\
Phu Phan sandstone & $75 \%$ quartz $(0.1-0.5 \mathrm{~mm}), 15 \%$ feldspar $(0.2-0.5 \mathrm{~mm}), 7 \%$ mica $(0.1-0.5 \mathrm{~mm})$, \\
& $3 \%$ lithic fragment $(0.1-1 \mathrm{~mm})$ \\
Phra Wihan sandstone & $72 \%$ quartz $(0.2-0.8 \mathrm{~mm}), 20 \%$ feldspar $(0.1-0.8 \mathrm{~mm}), 3 \%$ mica $(0.1-0.3 \mathrm{~mm})$, \\
& $3 \%$ rock fragment $(0.5-2 \mathrm{~mm}), 2 \%$ other $(0.5-1 \mathrm{~mm})$ \\
Phu Kradung siltstone & $70 \%$ lithic fragment $(0.1-0.3 \mathrm{~mm}), 18 \%$ quartz $(0.1-0.5 \mathrm{~mm}), 7 \%$ mica $(0.1-0.5 \mathrm{~mm})$, \\
& $3 \%$ feldspar $(0.1-0.5 \mathrm{~mm}), 2 \%$ other $(0.1-0.8 \mathrm{~mm})$ \\
\hline
\end{tabular}
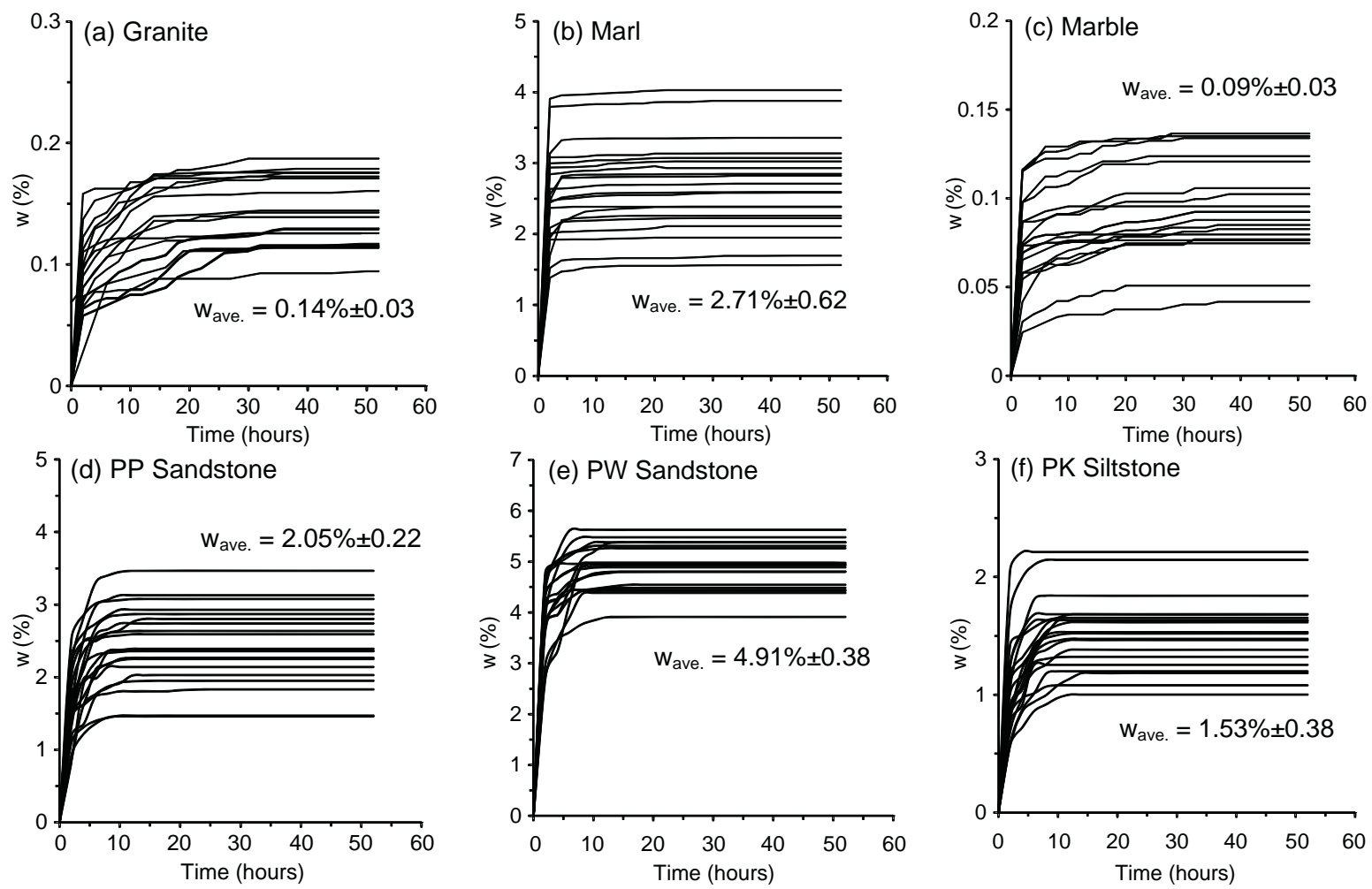

Fig. 1 Water content $(w)$ measured as a function of time.

imens were prepared to obtain rectangular blocks with nominal dimensions of $50 \times 50 \times 100 \mathrm{~mm}^{3}$ for triaxial compression tests. The specimens were cut and ground to obtain the perpendicularity and parallelism to comply with the ASTM standard practice ${ }^{27}$. Testing was carried out under dry and wet conditions. Under dry condition the specimens were dried in an oven for $24 \mathrm{~h}$ before testing. To wet the rock specimens, they were submerged in water in a pressure vacuum chamber at a negative pressure of $0.1 \mathrm{MPa}$. The vacuum chamber was connected to a vacuum pump (Air pump Sparmax Model TC$501 \mathrm{~V}$ ) capable of inducing $-1 \mathrm{~atm}$. Their weights were measured every two hours. The measurements were made outside the vacuum chamber, then the specimens were returned to the chamber. This pressure treatment was repeated until the weight remained unchanged. The average water content $\left(w_{\text {ave }}\right)$ of granite, marl, marble, PP sandstone, PW sandstone, and siltstone was $0.14 \%, 2.7 \%, 0.09 \%$, $2.05 \%, 4.9 \%$, and $1.5 \%$, respectively (Fig. 1 ).

Table 2 summarizes the physical properties of 
Table 2 Physical properties of rock specimens.

\begin{tabular}{lcccc}
\hline Rock types & Dry density $\left(\mathrm{g} / \mathrm{cm}^{3}\right)$ & Wet density $\left(\mathrm{g} / \mathrm{cm}^{3}\right)$ & Water content $w(\%)$ & Effective porosity $n(\%)$ \\
\hline Granite & $2.64 \pm 0.04$ & $2.65 \pm 0.06$ & $0.14 \pm 0.03$ & $0.37 \pm 0.06$ \\
Marl & $2.49 \pm 0.05$ & $2.55 \pm 0.05$ & $2.71 \pm 0.62$ & $6.7 \pm 1.4$ \\
Marble & $2.74 \pm 0.04$ & $2.74 \pm 0.04$ & $0.09 \pm 0.03$ & $0.26 \pm 0.07$ \\
PP Sandstone & $2.42 \pm 0.05$ & $2.47 \pm 0.04$ & $2.05 \pm 0.22$ & $4.97 \pm 0.51$ \\
PW Sandstone & $2.25 \pm 0.06$ & $2.36 \pm 0.04$ & $4.91 \pm 0.38$ & $11.00 \pm 0.97$ \\
PK Siltstone & $2.53 \pm 0.03$ & $2.57 \pm 0.02$ & $1.53 \pm 0.38$ & $3.88 \pm 0.98$ \\
\hline
\end{tabular}

the rock specimens.

\section{Testing equipment and methods}

The triaxial compression tests were performed on dry and wet specimens using a polyaxial load frame $^{28}$. The polyaxial load frame applies constant lateral and axial stresses to rectangular rock specimens. Two pairs of $152 \mathrm{~cm}$ long cantilever beams were used to apply the lateral loads in mutually perpendicular directions. The outer end of each beam was pulled down by a dead weight placed on a lower steel bar linking the two opposite beams underneath. The beam inner end was hinged by a pin mounted between vertical bars on each side of the frame. During testing, all beams were arranged nearly horizontally, and hence a lateral compressive load results on the specimen was placed at the centre of the frame. The maximum lateral load was designed for $100 \mathrm{kN}$. The axial load was applied with a $1000-\mathrm{kN}$ hydraulic load cell connected to an electric oil pump via a pressure regulator. Constant and uniform axial and lateral stress pressures (confining pressures) were first applied to the rock specimens while the axial stress was increased at a constant rate until a failure occurred. In this study, the lateral stresses were equal, ranging $0,3,7$, and $12 \mathrm{MPa}$, and the constant axial loading rates ranged 0.001 , $0.01,0.1,1$, and $10 \mathrm{MPa} / \mathrm{s}$. Perforated neoprene sheets were placed at the interface between loading platens and rock surfaces to minimize the friction while allowing seepage for wet testing. The test was started by increasing the axial stress at the predefined rate using the electric pump and load cell. The axial and lateral strains were monitored by displacement gages with the accuracy of $0.001 \mathrm{~mm}$. The failure stresses were recorded and the mode of failure was examined.

\section{RESULTS}

Fig. 2 shows some post-test marble specimens under confining pressures $\left(\sigma_{3}\right)$ of $0,3,7$, and $12 \mathrm{MPa}$ with loading rates $\left(\partial \sigma_{1} / \partial t\right)$ of 1 and $0.001 \mathrm{MPa} / \mathrm{s}$

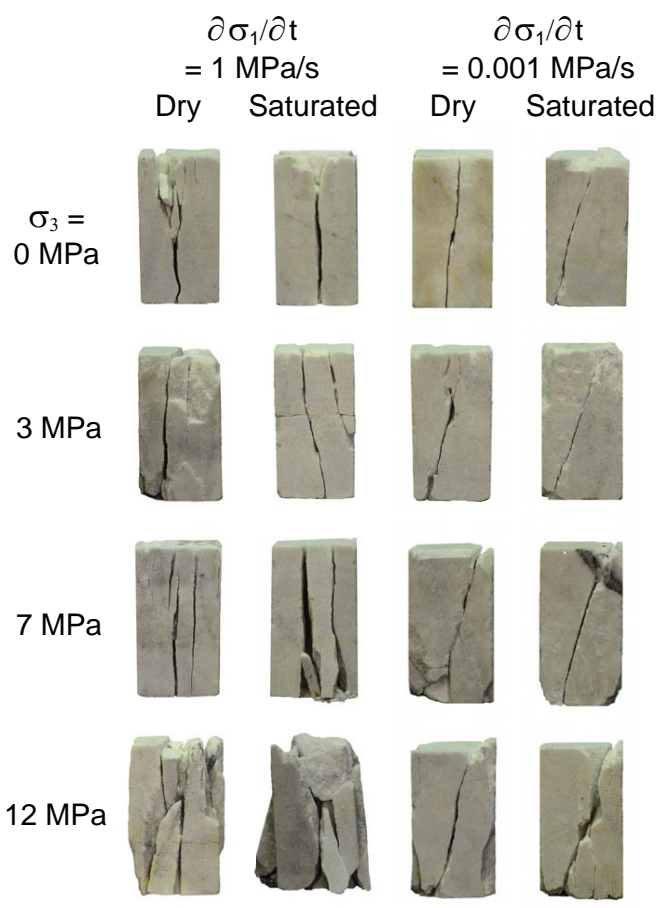

Fig. 2 Some post-test marble specimens with loading rate of 1 and $0.001 \mathrm{MPa} / \mathrm{s}$.

for both dry and wet conditions. Compressive shear failure was observed for low loading rate specimens while extension failure was found in the high loading rate specimens. High confining pressures resulted in multiple shear fractures. Figs. 3 and 4 show the stress-strain curves obtained from different loading rates and confining pressures. The stress-strain relations are nonlinear, particularly under low loading rates. Rock specimens under high loading rate showed a higher strength than those under low loading rate (Table 3 ). This effect becomes larger under higher confining pressures (Fig. 5) as has been observed in other studies $^{8,28,29}$. The strength of the dry specimens was always greater than that of the wet one as has been found for Denizli travertine ${ }^{1}$, homogeneous 

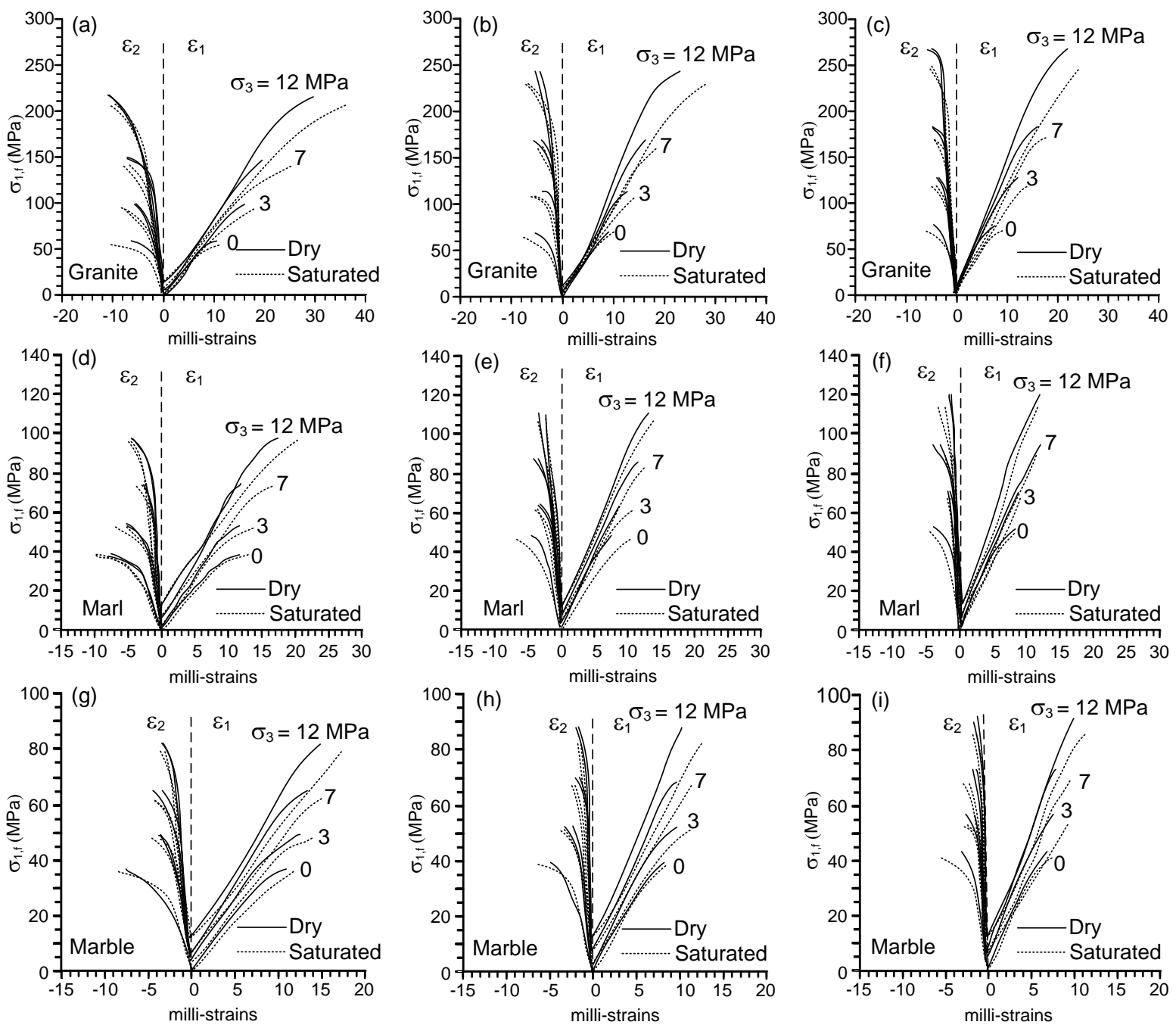

Fig. 3 Stress-strain curves obtained from $(a-c)$ granite, $(d-f)$ marl, and $(g-i)$ marble specimens with loading rates of (a, d, g) $0.001 \mathrm{MPa} / \mathrm{s}$, (b, e, h) $0.1 \mathrm{MPa} / \mathrm{s}$, and (c, f, i) $1 \mathrm{MPa} / \mathrm{s}$.

Indian granite ${ }^{8}$, sandstone ${ }^{3,7,9}$, and limestone ${ }^{3,7}$. The differences in strengths between the wet and dry specimens increased with confining pressures. The rock specimens with higher porosity (PW sandstone) yielded larger strength difference than those with lower porosity (granite, marl, marble, PP and PK sandstones).

Assuming that the rock specimens are linearly elastic and isotropic, the elastic modulus and Poisson's ratio of the rocks can be determined using the following equations ${ }^{30}$ :

$$
\begin{aligned}
& \varepsilon_{1}=\sigma_{1} / E_{1}-v\left(\sigma_{2} / E_{2}+\sigma_{3} / E_{3}\right) \\
& \varepsilon_{2}=\sigma_{2} / E_{2}-v\left(\sigma_{1} / E_{1}+\sigma_{3} / E_{3}\right) \\
& \varepsilon_{3}=\sigma_{3} / E_{3}-v\left(\sigma_{1} / E_{1}+\sigma_{2} / E_{2}\right)
\end{aligned}
$$

where $\varepsilon_{1}$ is the major principal strain (axial), $\varepsilon_{2}$, and $\varepsilon_{3}$ are the lateral principal strains (measured separately), $E_{1}$ is the elastic modulus along the major principal directions, $E_{2}$ and $E_{3}$ are the elastic moduli along the minor principal directions, and $v$ is Poisson's ratio for each specimen. The elastic parameters are determined from the tangent of stressstrain curves at $50 \%$ failure stress. In this study the lateral confining stress coefficients were equal $\left(\sigma_{2}=\sigma_{3}\right)$.

The results show that the elastic moduli increased with loading rate (Fig. 6). The elastic moduli of the dry specimens were higher than those of the wet specimens. Poisson's ratios of dry specimens were slightly lower than those of the wet specimens (Fig. 7). These results generally agree with the results obtained on low porosity meta-sedimentary rocks ${ }^{13}$, on sandstone and limestone ${ }^{3,7}$, and on 

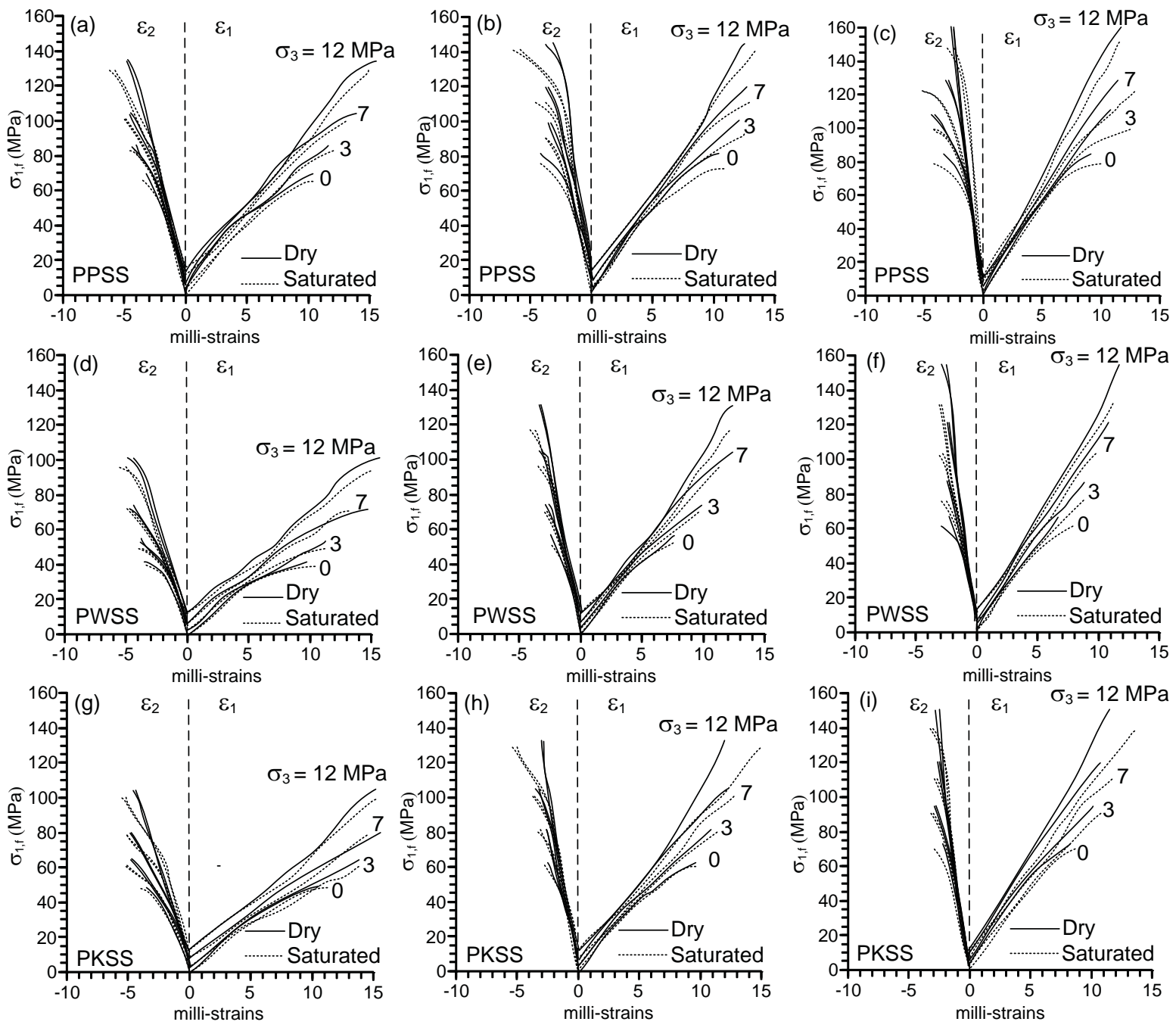

Fig. 4 Same as Fig. 3 for (a-c) PP sandstone, (d-f) PW sandstone, and (g-i) PK siltstone specimens.

gypsum ${ }^{14}$. Under a loading rate of $0.001 \mathrm{MPa} / \mathrm{s}$ the elastic modulus and Poisson's ratio under dry and wet conditions were comparable. This suggests that the pore pressure has an insignificant effect on the rock strengths if there is sufficient time to allow water to flow out of the specimens. The elastic modulus $(E)$ and Poisson's ratio $(v)$ can be presented as a function of the loading rate as

$$
\begin{aligned}
& E=v\left(\frac{\partial \sigma_{1}}{\partial t}\right)^{\chi} \\
& v=\eta \ln \left(\frac{\partial \sigma_{1}}{\partial t}\right)+\iota
\end{aligned}
$$

where $v, \chi, \eta$, and $\iota$ are empirical constants (Figs. 6 and 7). A power function can be used to describe the increase of rock elastic modulus with the loading rate $^{31}$. The above equations were used to calibrate the loading rate effect on the rock strengths in the next section.

\section{Calibrating loading rate effects}

This section describes the effect of loading rate on the strengths of wet specimens, and hence reveals the effect of effective confining pressure. Here, $\sigma_{1, \text { f,dry }}$ represents the original strength of dry specimens under various loading rates and confining pressures. $\sigma_{1, \mathrm{f}, \mathrm{dry}}^{*}$ is taken here as the adjusted strength of dry specimens corresponding to $\partial \sigma_{1} / \partial t=0.1 \mathrm{MPa} / \mathrm{s}$. The increase of the strengths with loading rate can be represented by a logarithmic function:

$$
\sigma_{1, \mathrm{f}, \mathrm{dry}}=\alpha \ln \left(\frac{\partial \sigma_{1}}{\partial t}\right)+\beta
$$

where $\alpha$ and $\beta$ are empirical constants (Table 4). 
Table 3 Major principal stresses at failure $\sigma_{1, \mathrm{f}}(\mathrm{MPa})$ under various confining pressures $\sigma_{3}$ and loading rates $\partial \sigma_{1} / \partial t$.

\begin{tabular}{|c|c|c|c|c|c|c|c|c|c|c|c|c|c|}
\hline \multirow{2}{*}{$\begin{array}{l}\sigma_{3} \\
(\mathrm{MPa})\end{array}$} & \multirow{2}{*}{$\begin{array}{l}\partial \sigma_{1} / \partial t \\
(\mathrm{MPa} / \mathrm{s})\end{array}$} & \multicolumn{2}{|c|}{ Granite } & \multicolumn{2}{|c|}{ Marl } & \multicolumn{2}{|c|}{ Marble } & \multicolumn{2}{|c|}{ PP Sandstone } & \multicolumn{2}{|c|}{ PW Sandstone } & \multicolumn{2}{|c|}{ PK Siltstone } \\
\hline & & Dry & Sat. & Dry & Sat. & Dry & Sat. & Dry & Sat. & Dry & Sat. & Dry & Sat. \\
\hline \multirow[t]{5}{*}{0} & 0.001 & 59 & 54 & 38 & 38 & 37 & 36 & 68 & 67 & 41 & 39 & 46 & 45 \\
\hline & 0.01 & 64 & 59 & 42 & 41 & 38 & 37 & 76 & 74 & 48 & 48 & 58 & 57 \\
\hline & 0.1 & 70 & 64 & 47 & 46 & 40 & 39 & 80 & 79 & 54 & 51 & 65 & 64 \\
\hline & 1 & 77 & 70 & 53 & 51 & 43 & 41 & 85 & 82 & 67 & 60 & 74 & 72 \\
\hline & 10 & 86 & 78 & 62 & 58 & 46 & 44 & 93 & 87 & 79 & 66 & 80 & 77 \\
\hline \multirow[t]{5}{*}{3} & 0.001 & 99 & 93 & 53 & 52 & 49 & 48 & 87 & 85 & 53 & 51 & 65 & 59 \\
\hline & 0.01 & 104 & 98 & 57 & 56 & 51 & 49 & 93 & 91 & 65 & 63 & 75 & 72 \\
\hline & 0.1 & 114 & 107 & 63 & 61 & 53 & 52 & 98 & 94 & 73 & 70 & 83 & 80 \\
\hline & 1 & 128 & 119 & 71 & 67 & 56 & 53 & 108 & 100 & 86 & 76 & 95 & 90 \\
\hline & 10 & 142 & 128 & 81 & 73 & 62 & 56 & 121 & 106 & 103 & 80 & 103 & 94 \\
\hline \multirow[t]{5}{*}{7} & 0.001 & 147 & 140 & 74 & 72 & 65 & 63 & 104 & 102 & 71 & 69 & 80 & 77 \\
\hline & 0.01 & 158 & 150 & 79 & 77 & 67 & 65 & 110 & 107 & 87 & 86 & 97 & 92 \\
\hline & 0.1 & 169 & 159 & 85 & 81 & 69 & 67 & 118 & 114 & 103 & 95 & 105 & 102 \\
\hline & 1 & 182 & 169 & 93 & 88 & 73 & 69 & 131 & 124 & 120 & 103 & 120 & 112 \\
\hline & 10 & 203 & 181 & 103 & 93 & 82 & 73 & 142 & 127 & 134 & 105 & 130 & 116 \\
\hline \multirow[t]{5}{*}{12} & 0.001 & 214 & 205 & 99 & 97 & 83 & 80 & 130 & 127 & 100 & 95 & 106 & 100 \\
\hline & 0.01 & 225 & 214 & 104 & 102 & 85 & 82 & 138 & 133 & 120 & 110 & 123 & 117 \\
\hline & 0.1 & 243 & 229 & 111 & 107 & 88 & 84 & 146 & 139 & 130 & 118 & 134 & 130 \\
\hline & 1 & 267 & 248 & 120 & 114 & 93 & 87 & 157 & 147 & 154 & 130 & 152 & 140 \\
\hline & 10 & - & - & 130 & 118 & 103 & 92 & 167 & 152 & 178 & 130 & 161 & 145 \\
\hline
\end{tabular}
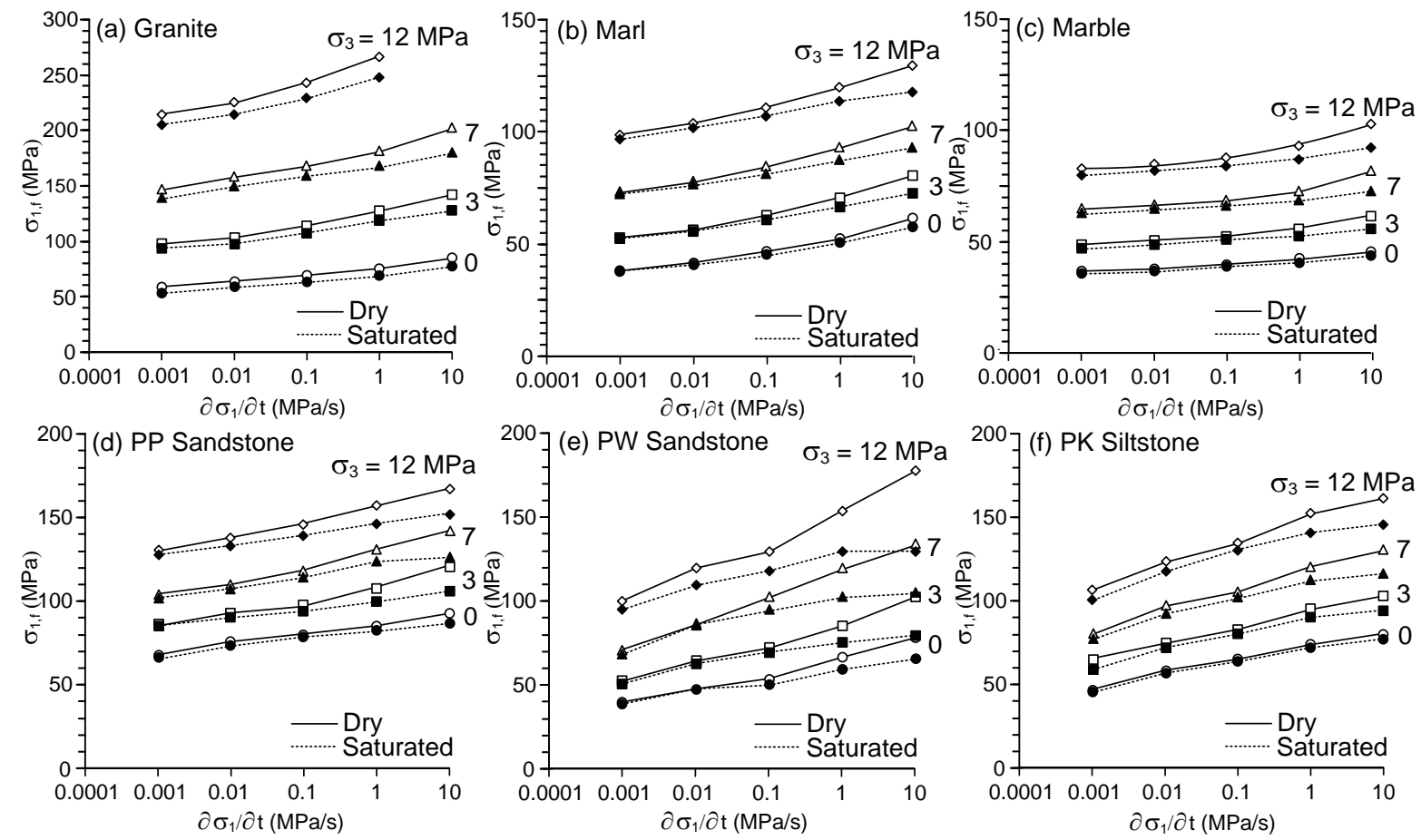

Fig. 5 Major principal stress $\left(\sigma_{1, \mathrm{f}}\right)$ as a function of loading rate $\left(\partial \sigma_{1} / \partial t\right)$. 

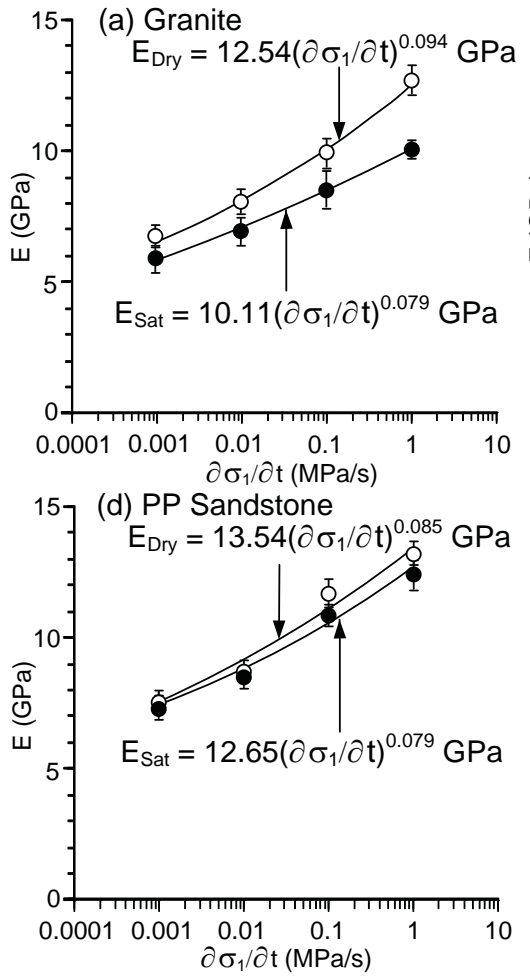

(b) Marl
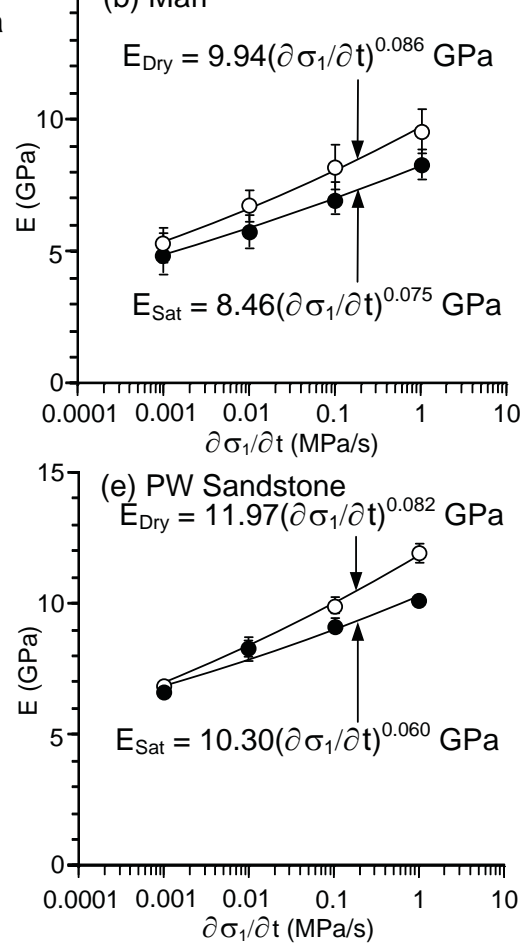
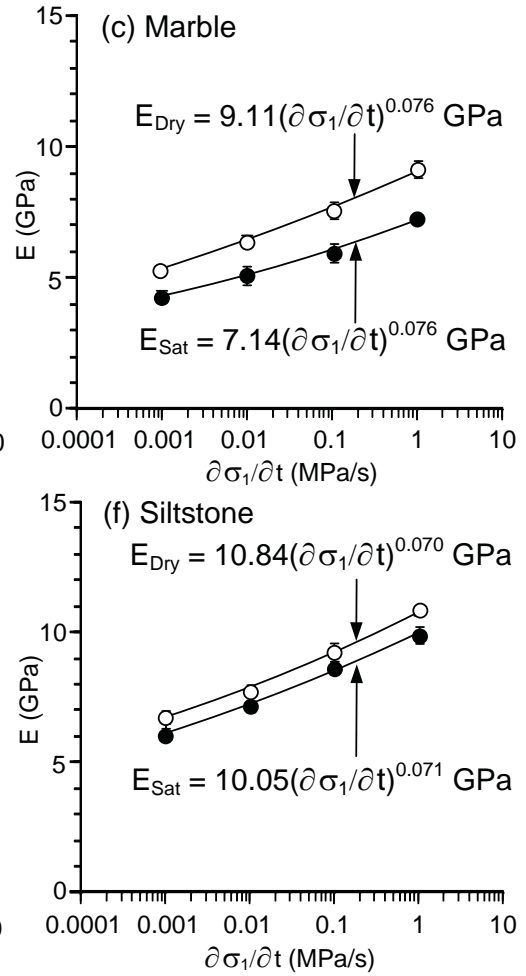

Fig. 6 Elastic modulus $(E)$ calculated as a function of loading rate $\left(\partial \sigma_{1} / \partial t\right)$.

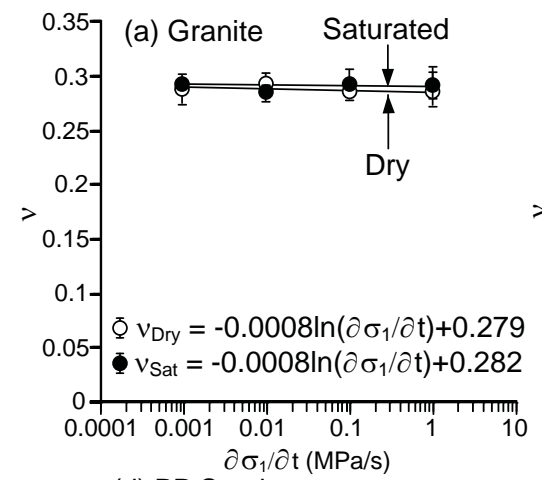

(d) PP Sandstone Saturated

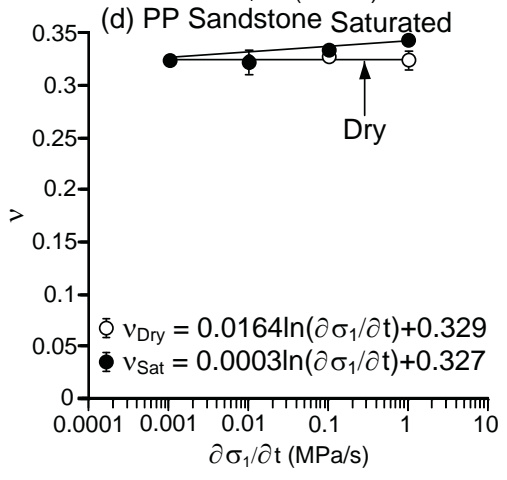

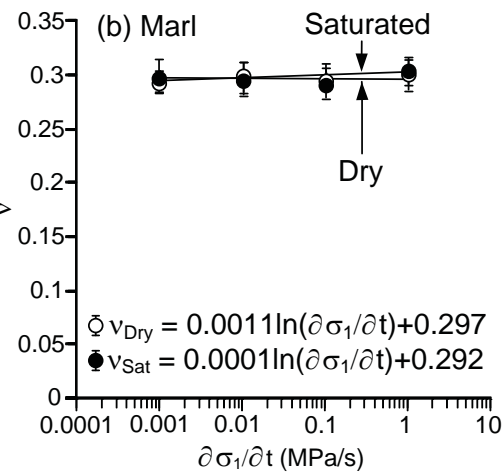

$0^{0.35}$ (e) PW Sandstone Saturated

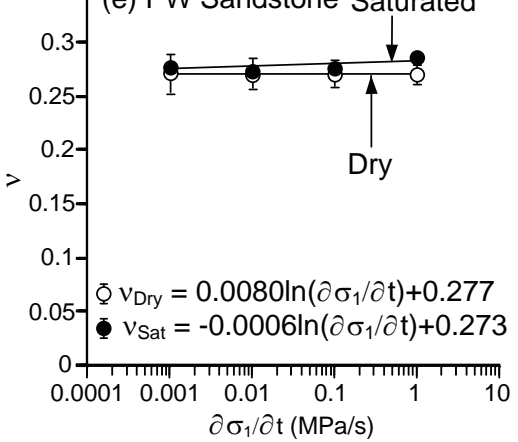

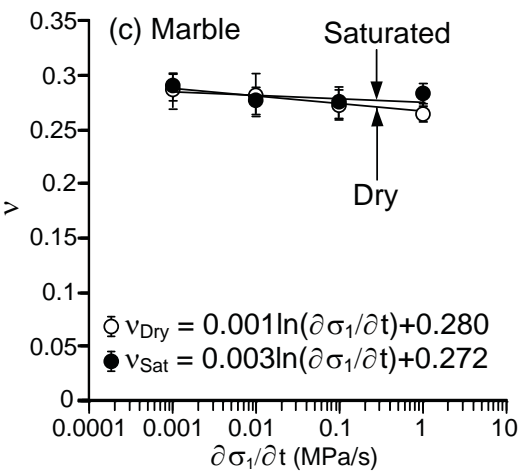

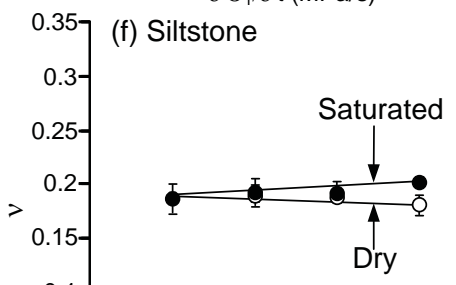

$\Phi v_{\text {Dry }}=0.0132 \ln \left(\partial \sigma_{1} / \partial t\right)+0.189$

$0.05-v_{\text {Sat }}=-0.0067 \ln \left(\partial \sigma_{1} / \partial \mathrm{t}\right)+0.189$

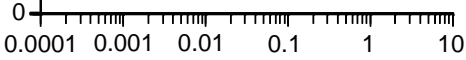
$\partial \sigma_{1} / \partial \mathrm{t}(\mathrm{MPa} / \mathrm{s})$

Fig. 7 Poisson's ratio $(v)$ calculated as a function of loading rate $\left(\partial \sigma_{1} / \partial t\right)$. 
Table 4 Empirical constants $\alpha$ and $\beta$ for strength and loading rate relation under dry condition.

\begin{tabular}{lrrr}
\hline Rock types & $\sigma_{3}(\mathrm{MPa})$ & $\alpha(1 / \mathrm{s})$ & $\beta(\mathrm{MPa})$ \\
\hline Granite & 0 & 2.881 & 77.77 \\
& 3 & 4.801 & 128.31 \\
& 7 & 5.906 & 185.40 \\
Marl & 12 & 7.643 & 263.56 \\
& 0 & 2.547 & 54.27 \\
& 3 & 3.053 & 71.97 \\
Marble & 7 & 3.192 & 93.95 \\
& 12 & 3.431 & 120.60 \\
& 0 & 0.999 & 43.10 \\
PP Sandstone & 3 & 1.351 & 57.30 \\
& 7 & 1.737 & 75.20 \\
& 12 & 2.085 & 95.20 \\
& 0 & 2.536 & 86.18 \\
PW Sandstone & 3 & 3.605 & 109.70 \\
& 7 & 4.004 & 130.70 \\
& 12 & 4.213 & 156.82 \\
PK Siltstone & 0 & 4.123 & 67.30 \\
& 7 & 5.255 & 88.10 \\
& 12 & 6.918 & 118.87 \\
& 0 & 8.247 & 155.41 \\
& 3 & 3.648 & 73.00 \\
& 12 & 4.169 & 93.80 \\
& & 5.368 & 118.82 \\
& 6.019 & 149.04 \\
\hline
\end{tabular}

To correlate the specimen strength under identical confining pressure but with different loading rates, (3) can be rewritten as

$$
\begin{aligned}
& \sigma_{1, \mathrm{f} \text {,dry }}=\alpha \ln \left(\frac{\partial \sigma_{1}}{\partial t}\right)_{\mathrm{i}}+\beta \\
& \sigma_{1, \mathrm{f} \text {,dry }}^{*}=\alpha \ln 0.1+\beta
\end{aligned}
$$

where $\sigma_{1, \text { f,dry }}$ is the strength of any dry specimen, $\sigma_{1, \mathrm{f}, \mathrm{dry}}^{*}$ is the strength of the dry specimen tested under loading rate of $0.1 \mathrm{MPa} / \mathrm{s}$. Subtracting (4) from (5), we obtain:

$$
\sigma_{1, \mathrm{f}, \mathrm{dry}}^{*}=\sigma_{1, \mathrm{f}, \mathrm{dry}}+\alpha\left[\ln 0.1-\ln \left(\frac{\partial \sigma_{1}}{\partial t}\right)_{\mathrm{i}}\right] .
$$

Assuming that the effects of loading rate equally act on the dry and wet specimens, the adjusted strengths obtained from the dry testing are used to quantitatively correct for the loading rate effect arising from the wet testing. The adjusted strengths of the wet specimens can therefore be calculated from:

$$
\begin{aligned}
\Delta \sigma_{1, \mathrm{f}, \mathrm{dry}}^{*} & =\sigma_{1, \mathrm{f} \text {,dry }}-\sigma_{1, \mathrm{f}, \mathrm{dry}}^{*} \\
\sigma_{1, \mathrm{f} \text {,wet }}^{*} & =\sigma_{1, \mathrm{f} \text {,wet }}-\Delta \sigma_{1, \mathrm{f}, \mathrm{wet}}^{*}
\end{aligned}
$$

with $\Delta \sigma_{1, \mathrm{f} \text {,wet }}^{*}=\Delta \sigma_{1, \mathrm{f}, \mathrm{dry}}^{*}$.

Fig. 8 shows the adjusted strengths plotted as a function of confining pressure under dry and wet conditions for the equivalent loading rate of $0.1 \mathrm{MPa} / \mathrm{s}$. For both conditions, compressive strengths increase principal stress linearly with the confining pressure. The adjusted wet strengths are lower than those of the dry ones.

The Mohr-Coulomb criterion is applied to calculate the influence of the pore pressure under a triaxial stress state ${ }^{32}$ :

$$
\sigma_{1, \mathrm{f}}^{\prime}-\sigma_{3}^{\prime}=\sigma_{\mathrm{c}}+\sigma_{3}^{\prime}\left[\tan ^{2}\left(\frac{\pi}{4}+\frac{\phi}{2}\right)-1\right]
$$

where $\sigma_{1, \mathrm{f}}^{\prime}$ is the effective strength, $\sigma_{3}^{\prime}$ is the confining pressure, $\sigma_{\mathrm{c}}$ is the uniaxial compressive strength, and $\phi$ is the internal friction angle.

Based on the Coulomb strength criterion the cohesion $(c)$ and internal friction angle $(\phi)$ of the rocks can be determined. The Coulomb criterion in terms of the principal stress coefficients at the failure $\left(\sigma_{1, \mathrm{f}}, \sigma_{3, \mathrm{f}}\right)$ and the uniaxial compressive strength $\left(\sigma_{\mathrm{c}}\right)$ can be written as ${ }^{30}$ :

$$
\begin{aligned}
\sigma_{1, \mathrm{f}} & =\sigma_{\mathrm{c}}+\sigma_{3, \mathrm{f}} \tan ^{2} \alpha \\
c & =\frac{\sigma_{\mathrm{c}}}{2 \tan \alpha} \\
\phi & =2 \alpha-\pi / 2 .
\end{aligned}
$$

The cohesion and friction angle of intact rock can be obtained from regression analyses of the compressive strength data ${ }^{30}$. These data include one value of uniaxial compressive strength $\left(\sigma_{\mathrm{c}}\right)$ and a set of major $\left(\sigma_{1, \mathrm{f}}\right)$ and minor $\left(\sigma_{3, \mathrm{f}}\right)$ principal stresses at failure obtained under the same loading rate (Table 3 and Fig. 5). The regression is performed on (8) by using $\sigma_{\mathrm{c}}$, and $\sigma_{1, \mathrm{f}}$ and $\sigma_{3, \mathrm{f}}$ coefficients (under dry condition with the same loading rate) as input to obtain a constant parameter $\alpha$ (as output). The regression results show good correlation $\left(R^{2} \geqslant 0.9\right)$ between (8) and the test data (Table 5). The parameter $\alpha$ is then used to calculate the cohesion and friction angle by using (9) and (10). The $c$ and $\phi$ values for each loading rate are summarized in Table 5 and are plotted as a function of loading rate in Fig. 9. They tend to increase with loading rate for all rock types, which supports the results shown in Fig. 5 that rocks under 

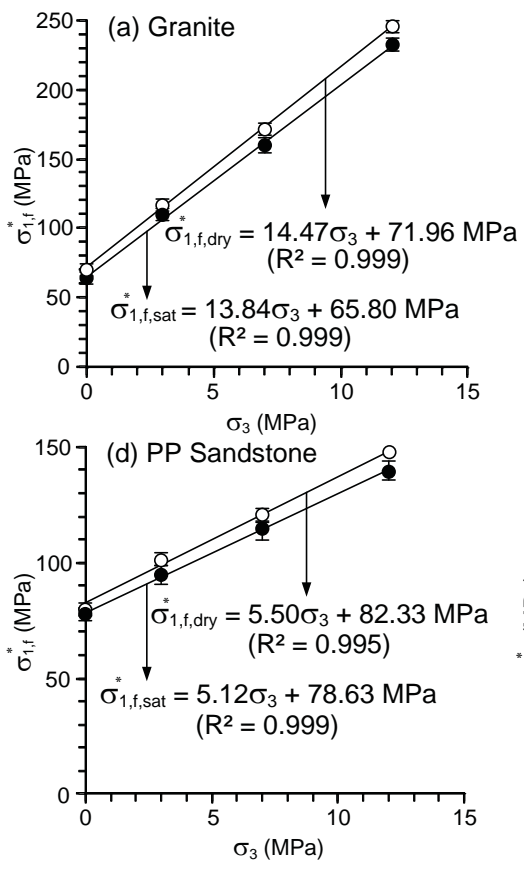
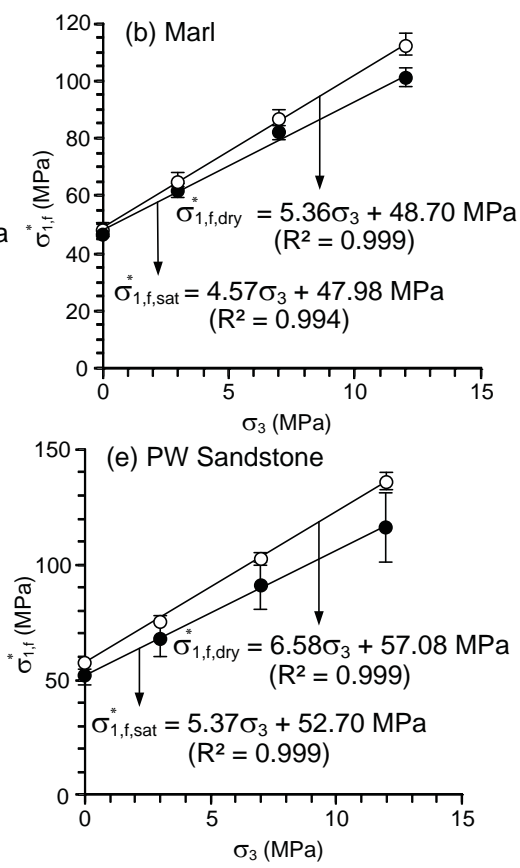
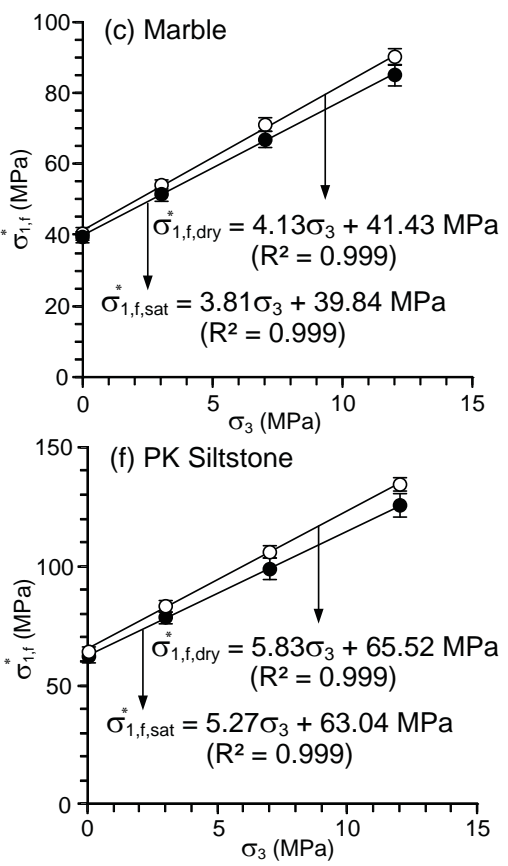

Fig. 8 Adjusted strengths $\left(\sigma_{1, \mathrm{f}}^{*}\right)$ as a function of confining pressure $\left(\sigma_{3}\right)$.

Table 5 Cohesions, friction angles and coefficients of correlation under dry condition for each loading rate.

\begin{tabular}{llcccccc}
\hline$\partial \sigma_{1} / \partial t$ & Parameters & Granite & Marl & Marble & PP Sandstone & PW Sandstone & PK Siltstone \\
\hline 0.001 & $c$ (MPa) & 8.1 & 8.1 & 9.5 & 15.1 & 9.1 & 10.6 \\
& $\phi$ (degrees) & 58 & 41 & 36 & 42 & 42 & 41 \\
& $R^{2}$ & 0.986 & 0.972 & 0.979 & 0.985 & 0.984 & 0.996 \\
0.01 & $c$ (MPa) & 8.7 & 9.3 & 9.8 & 16.4 & 10.1 & 11.8 \\
& $\phi$ (degrees) & 59 & 42 & 36 & 42 & 46 & 44 \\
& $R^{2}$ & 0.985 & 0.973 & 0.982 & 0.981 & 0.977 & 0.993 \\
0.1 & $c$ (MPa) & 9.4 & 10.4 & 10.2 & 17.6 & 11.2 & 13.0 \\
& $\phi$ (degrees) & 60 & 42 & 36 & 43 & 47 & 45 \\
& $R^{2}$ & 0.976 & 0.972 & 0.964 & 0.996 & 0.998 & 0.982 \\
& $c$ (MPa) & 10.0 & 11.6 & 10.5 & 18.9 & 12.3 & 14.2 \\
& $\phi$ (degrees) & 61 & 43 & 36 & 43 & 47 & 45 \\
& $R^{2}$ & 0.973 & 0.963 & 0.988 & 0.995 & 0.992 & 0.987 \\
& $c$ (MPa) & 10.6 & 12.7 & 10.9 & 20.1 & 13.3 & 15.4 \\
& $\phi$ (degrees) & 63 & 43 & 37 & 45 & 52 & 49 \\
& $R^{2}$ & 0.971 & 0.985 & 0.974 & 0.975 & 0.996 & 0.981 \\
\hline
\end{tabular}

high loading rate show a higher strength than those under low loading rate. The highest friction angles are obtained from the granite specimens because they are composed mainly of crystalline quartz and plagioclase and have low porosity. Nevertheless, the mineral compositions are also one of the main factors governing the friction angles. This is evidenced by the fact that the low porosity marble shows lower friction angle than those of the sandstones. This is because the marble specimens are composed mainly of calcite while the sandstone specimens are composed of stronger minerals (quartz, feldspar and lithic fragment), and hence show higher friction angle.

Since differential stress is unaffected by the pore pressure, (7) can be rewritten as

$\sigma_{1, \mathrm{f}, \mathrm{wet}}^{*}-\sigma_{3}=\sigma_{\mathrm{c}, \mathrm{f}, \mathrm{dry}}^{*}+\left(\sigma_{3}-P_{\mathrm{w}}\right)\left[\tan ^{2}\left(\frac{\pi}{4}+\frac{\phi}{2}\right)-1\right]$ 

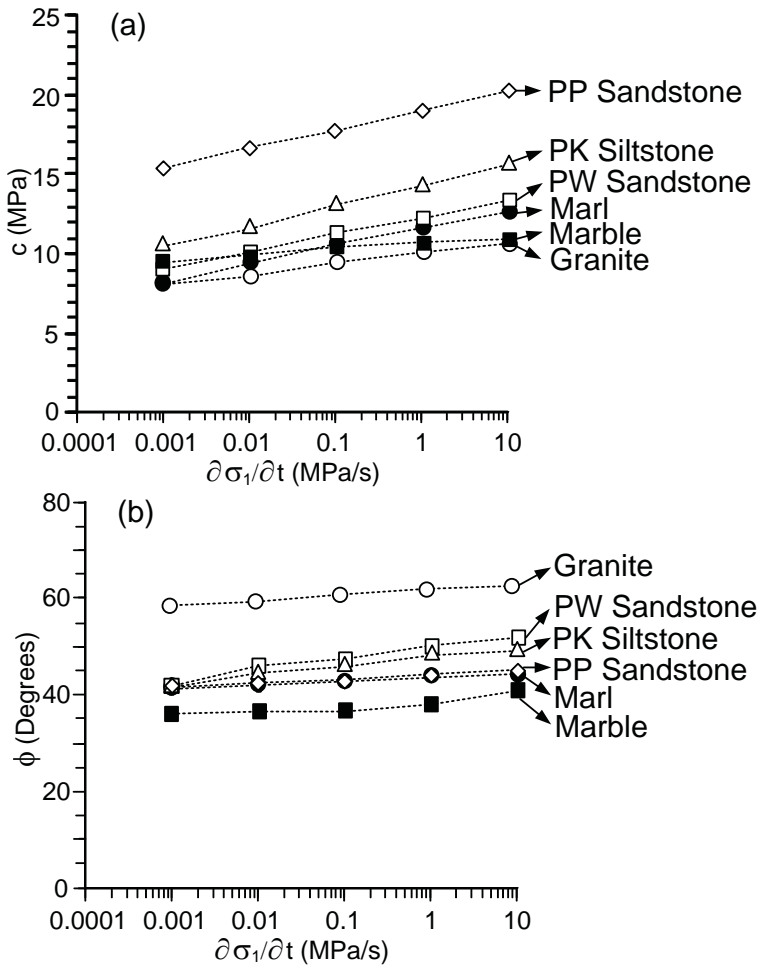

Fig. 9 (a) Cohesions and (b) friction angles as a function of loading rate for the dry condition.

where $P_{\mathrm{w}}$ is pore pressure. Solving for $P_{\mathrm{w}}$ in (11) the following relation can be obtained:

$$
P_{\mathrm{w}}=\sigma_{3}-\frac{\sigma_{1, \mathrm{f}, \mathrm{wet}}^{*}-\sigma_{3}-\sigma_{\mathrm{c}, \mathrm{f}, \mathrm{dry}}^{*}}{\tan ^{2}\left(\frac{\pi}{4}+\frac{\phi}{2}\right)-1} .
$$

Fig. 10 shows the adjusted strengths as a function of pore pressure. The data are fitted to the linear equation:

$$
\sigma_{1, \mathrm{f}, \mathrm{wet}}^{*}=\lambda+\kappa \sigma_{3}+\xi P_{\mathrm{w}}
$$

where parameters $\lambda, \kappa$, and $\xi$ are empirical constants. The adjusted strengths decrease linearly with increasing pore pressure. For all six rock types, it is apparent that the strength of the higher porosity rock (PW sandstone) is more sensitive to the pore pressure than those of the low porosity rock (granite, marl, and marble) in agreement with published results ${ }^{9}$.

As with the strength adjustment above, the effect of loading rate can be calibrated on the elastic parameters determined from the wet specimens. $E_{\text {dry }}$ and $v_{\text {dry }}$ represent the original elastic modulus and Poisson's ratio of dry specimens under various loading rates and confining pressures. $E_{\mathrm{dry}}^{*}$ and $v_{\mathrm{dry}}^{*}$ represent the adjusted elastic modulus and Poisson's ratio of dry specimens tested under $\partial \sigma_{1} / \partial t=$ $0.1 \mathrm{MPa} / \mathrm{s}$. The variations of the elastic modulus and Poisson's ratio with loading rate can be derived from (1) and (2). As with (6) it can be rewritten in a correlated form as

$$
\begin{aligned}
& E_{\mathrm{dry}}^{*}=E_{\mathrm{dry}}+v\left[0.1^{\chi}-\left(\frac{\partial \sigma_{1}}{\partial t}\right)_{\mathrm{i}}^{\chi}\right] \\
& v_{\mathrm{dry}}^{*}=v_{\mathrm{dry}}+\eta\left[\ln 0.1-\ln \left(\frac{\partial \sigma_{1}}{\partial t}\right)_{\mathrm{i}}\right] .
\end{aligned}
$$

The adjusted elastic modulus and Poisson's ratio of the wet specimens can be determined as

$$
\begin{aligned}
& E_{\mathrm{wet}}^{*}=E_{\mathrm{wet}}-\left(E_{\mathrm{dry}}-E_{\mathrm{dry}}^{*}\right) \\
& v_{\mathrm{wet}}^{*}=v_{\mathrm{wet}}-\left(v_{\mathrm{dry}}-v_{\mathrm{dry}}^{*}\right) .
\end{aligned}
$$

Figs. 11 and 12 show the adjusted elastic modulus and Poisson's ratio as a function of pore pressure. For all tested rocks, the adjusted elastic modulus values decrease linearly as the pore pressure increases. The adjusted Poisson's ratios slightly increase with pore pressure. This suggests that under the same stress condition the wet rocks can deform and dilate more than the dry ones.

An attempt is made to calculate the elastic moduli along the three loading directions. It is assumed here that Poisson's ratio $(v)$ of the rock is the same for all principal planes. They are averaged from all specimens for each rock types (Fig. 12). The adjusted elastic moduli along the major, intermediate, and minor principal directions $\left(E_{1}^{*}, E_{2}^{*}, E_{3}^{*}\right)$ can be calculated in Ref. 30:

$$
\begin{aligned}
& \varepsilon_{1}^{*}=\sigma_{1}^{*} / E_{1}^{*}-v\left(\sigma_{2}^{*} / E_{2}^{*}+\sigma_{3}^{*} / E_{3}^{*}\right) \\
& \varepsilon_{2}^{*}=\sigma_{2}^{*} / E_{2}^{*}-v\left(\sigma_{1}^{*} / E_{1}^{*}+\sigma_{3}^{*} / E_{3}^{*}\right) \\
& \varepsilon_{3}^{*}=\sigma_{3}^{*} / E_{3}^{*}-v\left(\sigma_{1}^{*} / E_{1}^{*}+\sigma_{2}^{*} / E_{2}^{*}\right)
\end{aligned}
$$

where $\varepsilon_{1}^{*}, \varepsilon_{2}^{*}$ and $\varepsilon_{3}^{*}$ are the major, intermediate, and minor principal strains at $50 \%$ strengths (Fig. 13). The elastic moduli along the three principal directions are similar, suggesting that the dry and wet specimens are isotropic. The elastic modulus values obtained from the wet specimens tend to be lower than those from the dry specimens.

\section{DISCUSSION}

After the effects of loading rate have been calibrated, the adjusted strengths from the wet specimens decrease with increasing pore pressure. When 

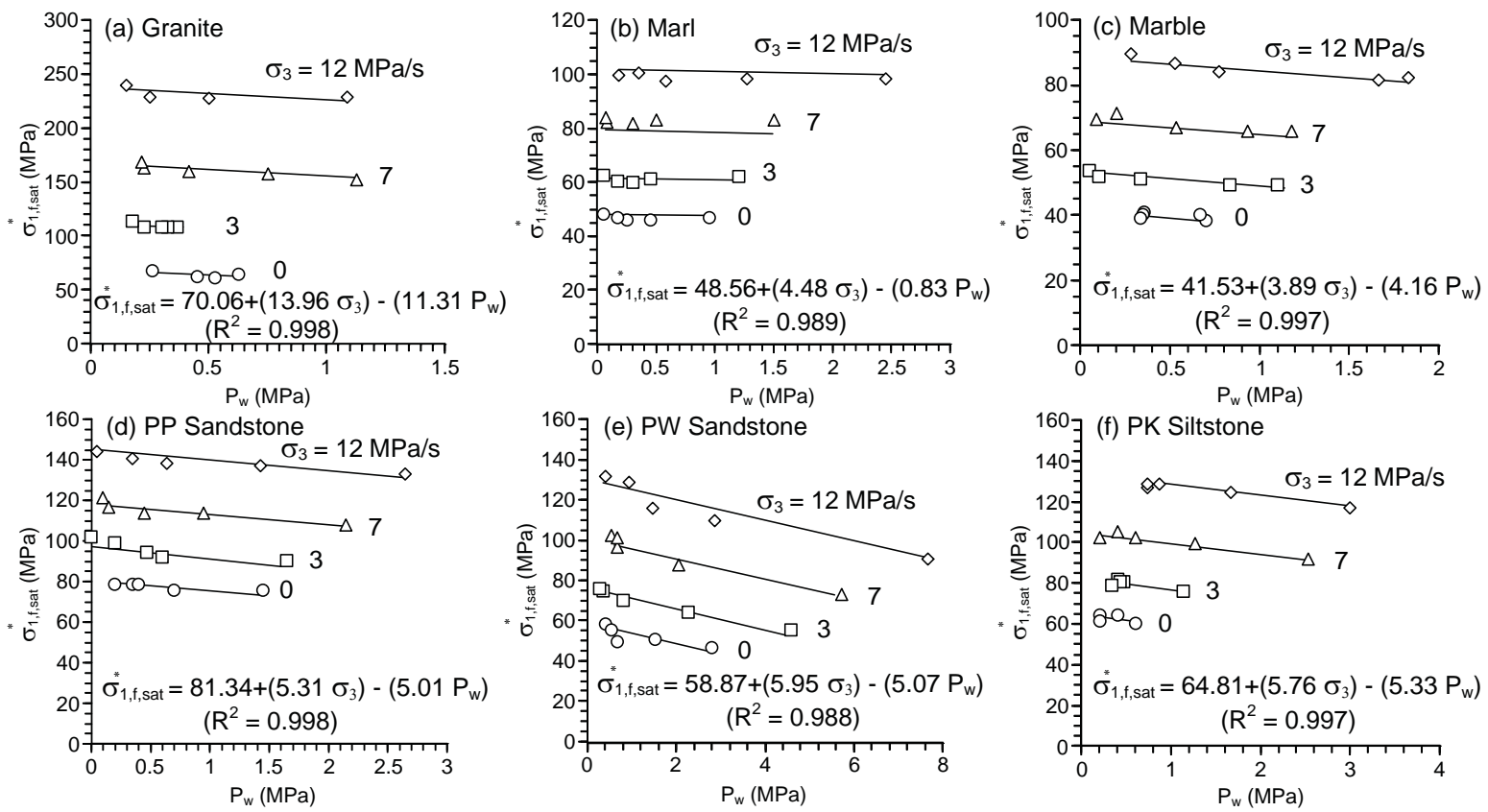

Fig. 10 Adjusted strengths $\left(\sigma_{1, \mathrm{f}}^{*}\right)$ as a function of pore pressure $\left(P_{\mathrm{w}}\right)$.
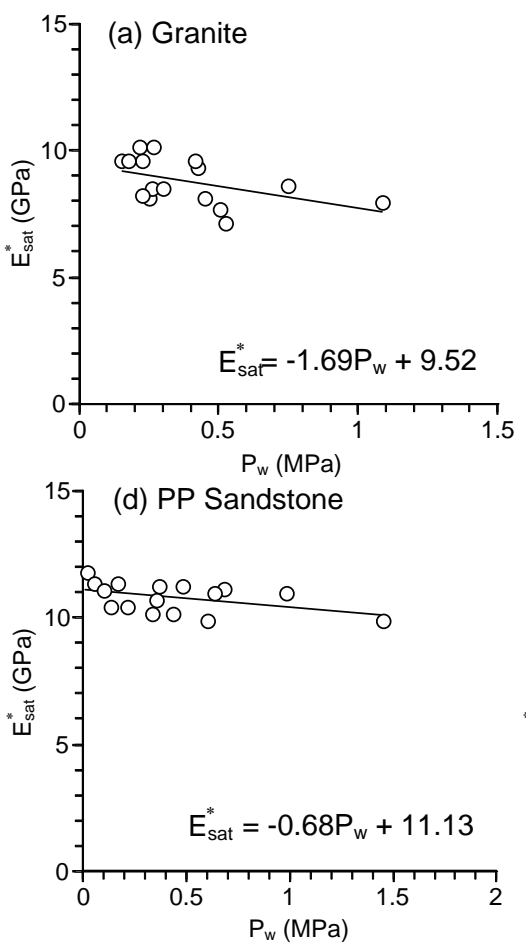

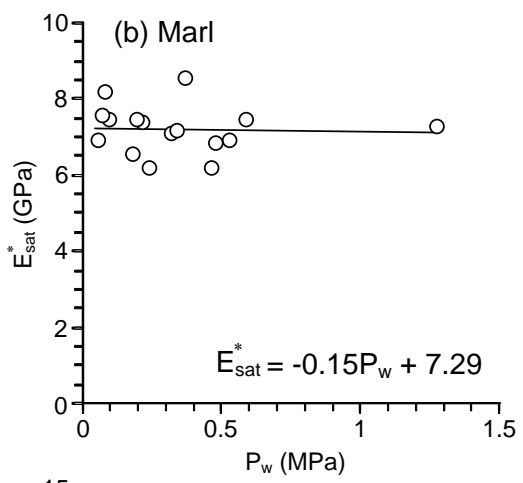

(e) PW Sandstone

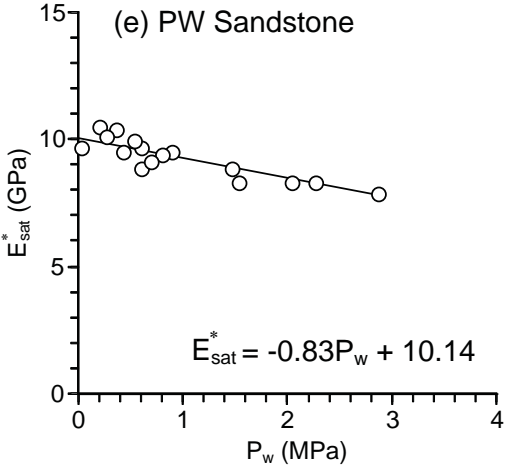

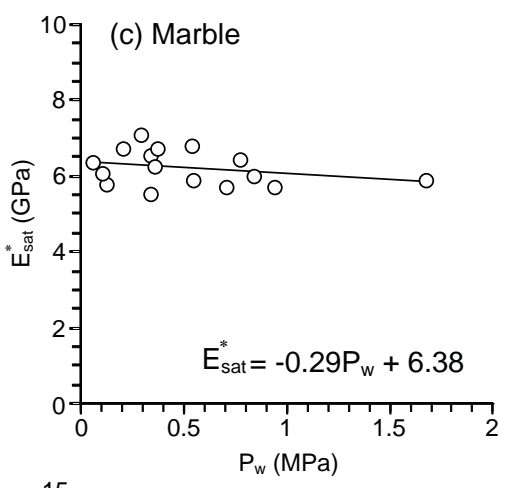

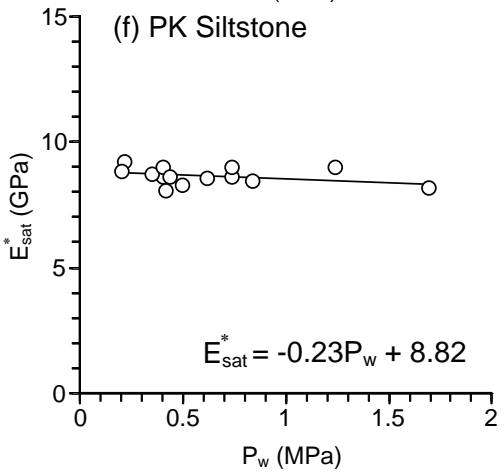

Fig. 11 Adjusted elastic modulus of wet specimen $\left(E_{\text {sat }}^{*}\right)$ as a function of pore pressure $\left(P_{\mathrm{w}}\right)$.

the pore pressure increases, the elastic modulus decreased and Poisson's ratios slightly increased in agreement with experimental observations ${ }^{6,9,14}$. The relations between compressive strength and elastic modulus with pore pressure can be best represented here by linear equations in agreement with previous work ${ }^{20}$.

Accuracy and reliability of the method to deter- 

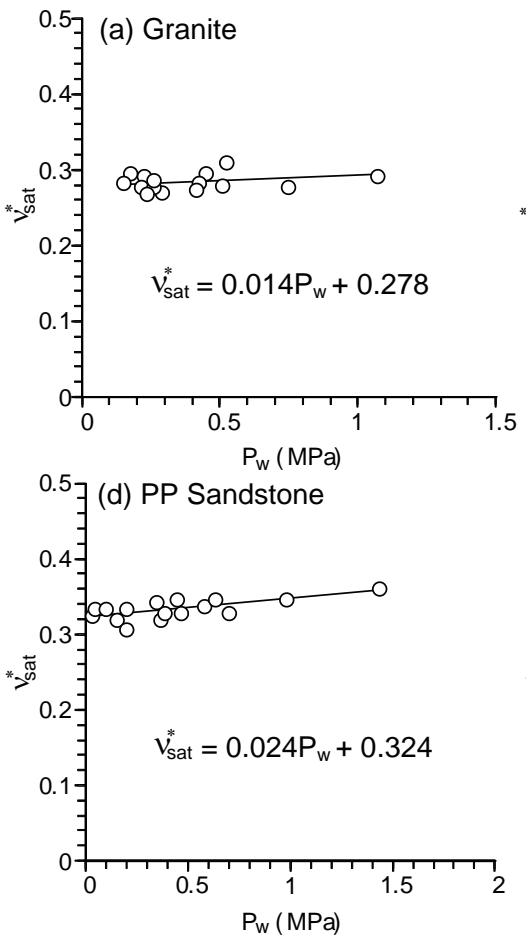
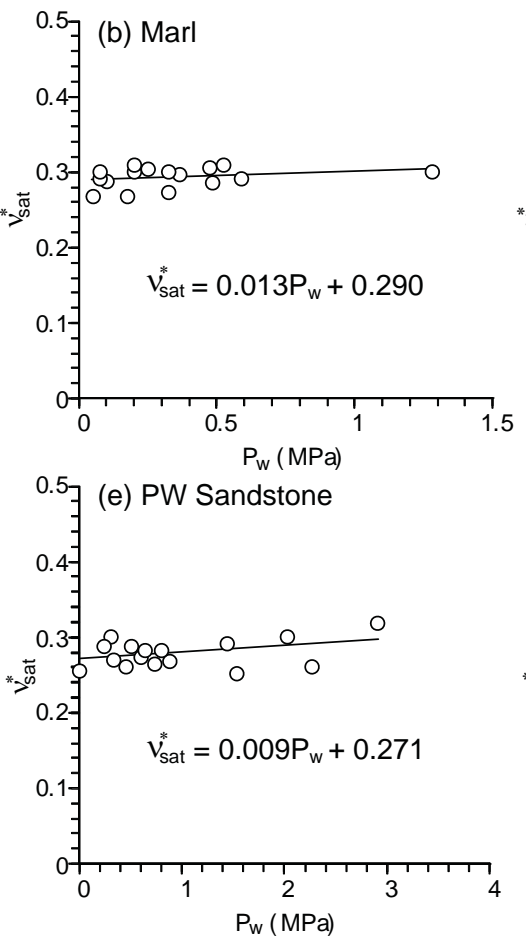
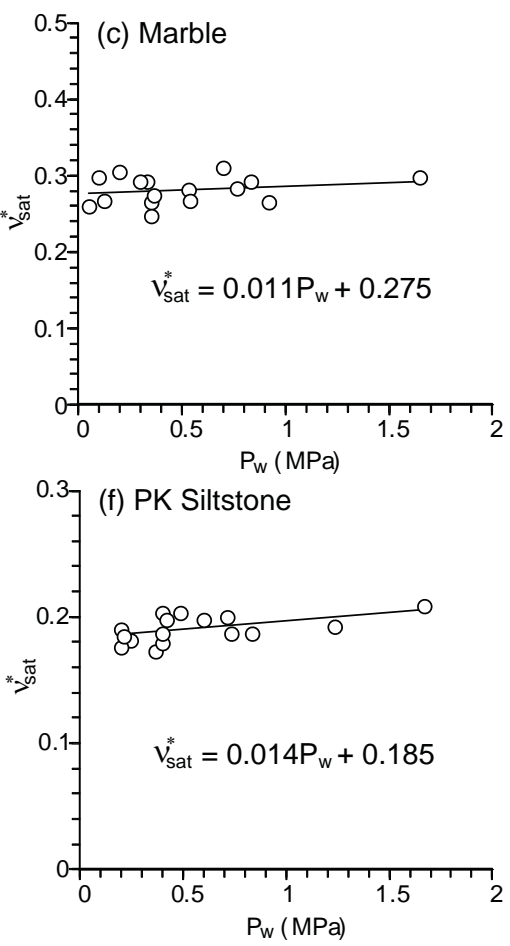

Fig. 12 Adjusted Poisson's ratio of wet specimen $\left(v_{\text {sat }}^{*}\right)$ as a function of pore pressure $\left(P_{\mathrm{w}}\right)$.

mine the effects of pore pressure proposed here depend on the range of the applied confining pressures and loading rates. A wider range of these boundary conditions may result in more accurate empirical parameters used in the equations describing the variations of the strengths, elastic moduli, and Poisson's ratios with the pore pressure. Thus a different form of the fitting equation may also be obtained. The discrepancies between the test results and the proposed equations, such as those of the elastic modulus-pore pressure relations (Fig. 11) and Poisson's ratio-pore pressure relations (Fig. 12), may be due to the intrinsic variability of the rock specimens. The large grained crystalline rocks (granite, marl, and marble) tend to show more variation than the fine grained clastic rocks (sandstones and siltstone). The water content used throughout the analysis is taken as an average value for each rock type to simplify the forms of the empirical equations used to fit the test data.

The pore spaces in the crystalline rocks are formed by the inter-crystalline boundaries and fissures while those in the clastic rocks are by the intergranular space. The differences in the pore space characteristics cannot be detected here. Both rock groups tended to show similar effects of the pore pressure. This may be due to the fact that the tested specimens were relatively small, with low effective porosity. For the low porosity rocks tested here the strengths are more sensitive to the confining pressure than to the pore pressure (Fig. 10). For the wet strengths the lower water content results in a lesser sensitivity the pore pressure. This suggests that the strength and deformability of low porosity rocks can be obtained from the test results under different confining pressures with more reliability than those from pore pressure determination.

Testing the wet specimens under low loading rates may represent the consolidated drained condition where the pore water has sufficient time to seep out of the rock matrix. On the other hand, the high loading rate testing may be equivalent to the consolidated undrained condition. The fast loading does not allow sufficient time for the pore water to seep out from the rock matrix. It should be noted that the maximum pore pressures determined from the proposed test method depends on the loading rate and confining pressure. A larger pore pressure magnitude may be obtained if a higher loading rate and confining pressure are applied.

This study aims at determining the effects of pore pressure on the short-term mechanical properties of ornamental and dimension stones. It is recognized that other factors not considered here do 

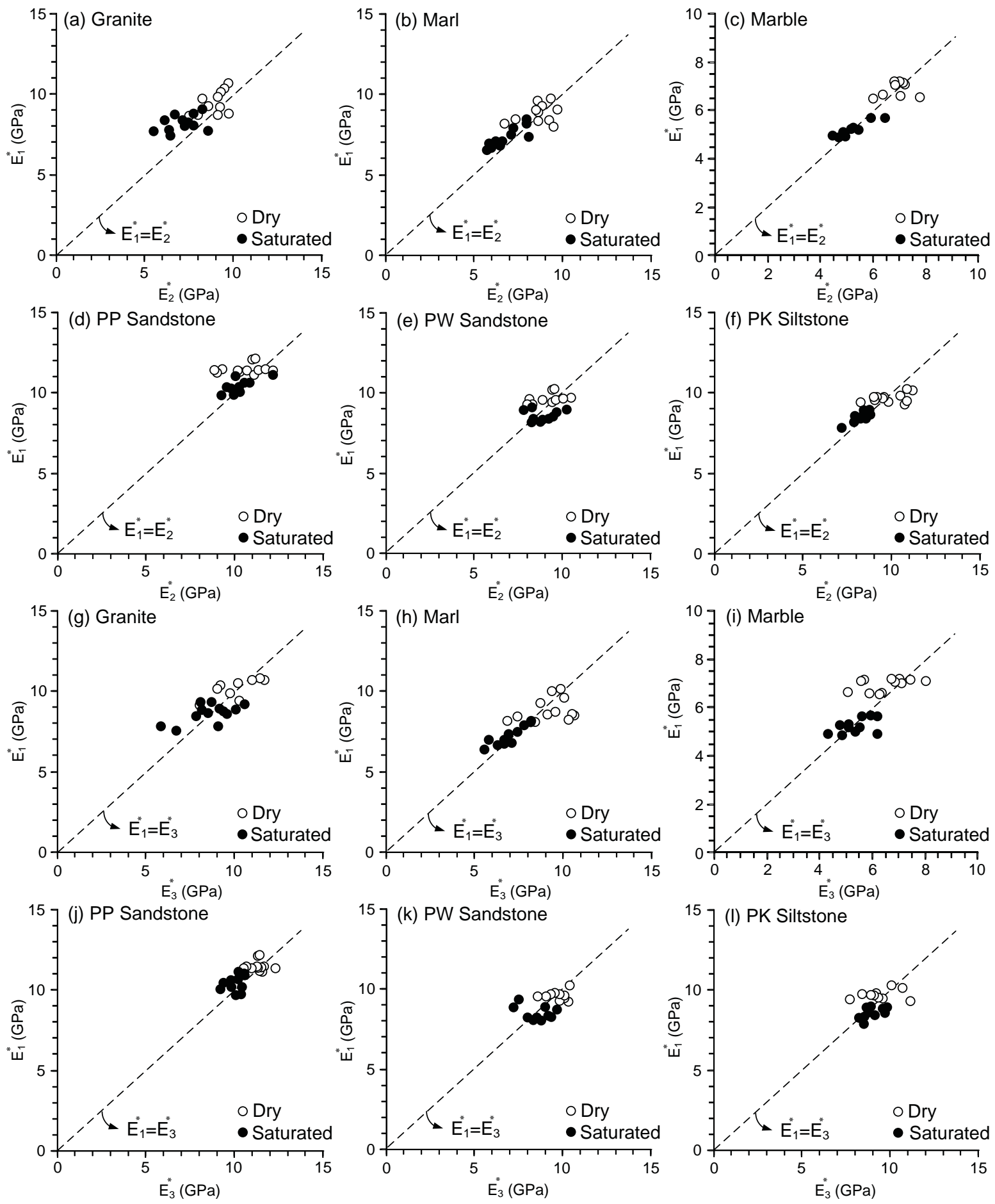

Fig. 13 Adjusted elastic modulus calculated along the major principal axis $E_{1}^{*}$ as a function of the elastic modulus along (a-f) intermediate and $(\mathrm{g}-\mathrm{l})$ minor principal axes.

affect the rock mechanical properties under wet condition, e.g., chemical alteration, time, grain (crystal) size, propagation of micro-cracks, and fissures. The proposed method is intended for general rock mechanics and rock engineering works, involving the well-established effective stress analysis ${ }^{32}$. The research can be readily applied by practitioner and designer for stability analysis of their decorating 
and building stone. The findings can be used to assess the mechanical stability of these ornamental stones as applied under environmental conditions with various moisture contents and confinements. For example, under wet conditions if the loading rate on the rocks can be determined, the strength and deformability of the rocks can be estimated. It should be noted that in this study only one sample is tested for each loading condition. A more reliable and rigorous calibration of the rock strength and pore pressure relations may be obtained if more samples are tested under each loading and boundary condition. Nevertheless, it is believed that the main conclusions drawn above remain valid even though the number of the test specimens does not comply with the relevant ASTM standard.

Acknowledgements: This study is funded by Suranaree University of Technology and by the Higher Education Promotion and National Research University of Thailand. Permission to publish this paper is gratefully acknowledged.

\section{REFERENCES}

1. Çobanoğlu I, Çelik SB (2012) Determination of strength parameters and quality assessment of Denizli travertines (SW Turkey). Eng Geol 129-30, 38-47.

2. Török A, Vásárhelyi B (2010) The influence of fabric and water content on selected rock mechanical parameters of travertine, examples from Hungary. Eng Geol 115, 237-45.

3. Vásárhelyi B (2005) Technical note statistical analysis of the influence of water content on the strength of the Miocene limestone. Rock Mech Rock Eng 38, 69-76.

4. Ludovico-Marques M, Chastre C, Vasconcelos G (2012) Modelling the compressive mechanical behaviour of granite and sandstone historical building stones. Construct Build Mater 28, 372-81.

5. Vásárhelyi B, Van P (2006) Influence of water content on the strength of rock. Eng Geol 84, 70-4.

6. Dyke CG, Dobereiner L (1991) Evaluating the strength and deformability of sandstones. $Q J$ Eng Geol Hydrogeol 24, 123-34.

7. Vásárhelyi B (2003) Some observations regarding the strength and deformability of sandstones in case of dry and saturated conditions. Bull Eng Geol Environ 62, 245-9.

8. Masuda K (2001) Effects of water on rock strength in a brittle regime. J Struct Geol 23, 1653-7.

9. Hawkins AB, McConnell BJ (1992) Sensitivity of sandstone strength and deformability to changes in moisture content. Q J Eng Geol Hydrogeol 25, 115-30.
10. White JM, Mazurkiewicz M (1989) Effect of moisture content on mechanical properties of Nemo coal, Moberly, Missouri U.S.A. Min Sci Tech 9, 181-5.

11. Ojo O, Brook N (1990) The effect of moisture on some mechanical properties of rock. Min Sci Tech 10, 145-56.

12. Kramadibrata S, Rai MA, Simangunsong GM, Arift I (2000) The influence of water content on strength characteristic of sandstone subject to triaxial test. In: Proceedings of the 19th International Conference on Ground Control in Mining, Morgantown, WV, USA, pp 372-7.

13. Li D, Wong LNY, Lui G, Zhang X (2012) Influence of water content and anisotropy on the strength and deformability of low porosity meta-sedimentary rocks under triaxial compression. Eng Geol 126, 46-66.

14. Yilmaz I (2010) Influence of water content on the strength and deformability of gypsum. Int $J$ Rock Mech Min Sci 47, 342-7.

15. Mahmutoğlu Y (2006) The effects of strain rate and saturation on a micro-cracked marble. Eng Geol 82, 137-44.

16. Palchik V (1999) Influence of porosity and elastic modulus on uniaxial compressive strength in soft brittle porous sandstones. Rock Mech Rock Eng 32, 303-9.

17. Palchik V, Hatzor YH (2004) The influence of porosity on tensile and compressive strength of porous chalks. Rock Mech Rock Eng 37, 331-41.

18. Palchik V, Hatzor YH (2002) Crack damage stress as a composite function of porosity and elastic matrix stiffness in dolomites and limestones. Eng Geol 63, 233-45.

19. Indraratna B, Ranjith PG (2001) Hydromechanical Aspects and Unsaturated Flow in Jointed Rock, A.A. Balkema, Tokyo.

20. Handin J, Hager RV, Friedman M, Feather JN (1963) Experimental deformation of sedimentary rocks under confining pressure: pore pressure tests. Am Assoc Petrol Geol Bull 47, 717-55.

21. Brace WF, Martin RJ (1968) A test of the law of effective stress for crystalline rocks of low porosity. Int $J$ Rock Mech Min Sci 5, 415-26.

22. Aldrich MJ (1969) Pore pressure effects on Berea sandstone subjected to experimental deformation. Geol Soc Am Bull 80, 1577-86.

23. Atherton M, Brotherton M, Mahawat C (1992) Integrated chemistry, textures, phase relations and modelling of a composite granodioritic-monzonitic batholith, Tak, Thailand. J Southeast Asian Earth Sci 7, 89-112.

24. Bunopas S (1992) Regional stratigraphic correlation in Thailand. In: National Conference on Geological Resources of Thailand: Potential for Future Development, Department of Mineral Resources, Bangkok.

25. Boonsener M, Sonpirom K (1997) Correlation of tertiary rocks in northeast, Thailand. In: International 
Conference on Stratigraphy and Tectonic Evolution of Southeast Asia and the South Pacific, Bangkok.

26. Fuenkajorn K (2005) Predictability of Barton's joint shear strength criterion using field-identification parameters. Suranaree J Sci Tech 12, 296-308.

27. ASTM C170/C170M-09 (2009) Standard Test Method for Compressive Strength of Dimension Stone, ASTM International, West Conshohocken, PA.

28. Fuenkajorn K, Sriapai T, Samsri P (2012) Effects of loading rate on strength and deformability of Maha Sarakham salt. Eng Geol 135-6, 10-23.

29. Masuda K, Mizutani H, Yamada I (1987) Experimental study of strain-rate dependence and pressure dependence of failure properties of granite. $J$ Phys Earth 35, 37-66.

30. Jaeger JC, Cook NGW, Zimmerman R (2007) Fundamentals of Rock Mechanics, 4th edn, Chapman and Hall, London.

31. Kenkhunthod N, Fuenkajorn K (2009) Loading rate effects on strength and stiffness of sandstones under confinement. In: Proceedings 2nd Thailand Symposium on Rock mechanics, Chonburi, Thailand, pp 271-82.

32. Goodman RE (1989) Introduction to Rock Mechanics, Wiley, New York. 